\title{
Validation of the California Preparedness to Teach Students with Autism (CAPTSA) Survey for Pre-Service Special Education Teachers
}

\author{
Susan G. Porter ${ }^{1}$, Teri A. Todd ${ }^{2}$, Maria C. Regalado ${ }^{3}$ \\ University of Redlands ${ }^{1}$, California State University ${ }^{2}$, Sacramento City College ${ }^{3}$
}

\begin{abstract}
As the number of students with Autism Spectrum Disorder (ASD) has grown dramatically, so as has the urgency to adequately prepare special educators to teach these students. In an effort to address this need, national and state standards have been adopted in order to identify a) evidenced-based treatments that teachers should know in order to be effective teachers of students with ASD, and b) competencies specifically needed to teach students with ASD. This study involved the development, piloting, and validation of a survey based upon 11 "established treatments" identified by the National Standards Project (NSP) and recently adopted California standards for teachers of students with ASD. The instrument was piloted with 84 pre-service special education teachers and interns in three California university-sponsored special education teacher preparation programs. Factor analysis demonstrated that the instrument has high construct validity. Implications for future administration of this instrument are discussed.
\end{abstract}

\section{Introduction}

Autism spectrum disorder (ASD) is the fastest growing disability in the United States. It is estimated that 1 in every 88 children are born with ASD [1]. This has put an incredible strain on an education system that is underprepared for these students. The education system is not only overwhelmed by the need for facilities and services for students with ASD, but also by an acute

shortage of teachers who are trained in best practices for teaching these students. University and district teacher preparation programs are struggling to keep up with the ever-changing field of ASD and to provide pre-service students with the tools required to be effective in the classroom.
Recent studies have verified the need to establish teacher preparation pathways and professional development guidelines for teaching staff who will work with students with autism spectrum disorders [2].

In response to this urgent need, the National Standards Project has recently established recommended treatments for serving students with ASD [3]. Additionally, several states including California recently legislated requirements for special education teacher preparation programs to incorporate competencies for teaching students with ASD into their curricula. This study seeks to learn more about the effects of these new national and state standards by surveying pre-service teachers' perceived knowledge and skills for teaching students with ASD at the end of their teacher preparation coursework. The authors developed and validated a survey for this purpose that is based on the National Standard's Project and the recently adopted California standards for special education teacher preparation programs.

\section{Theoretical frameworks}

\subsection{Standards-based approaches for ensur- ing teacher knowledge and skills}

Research on formal teacher preparation programs in the 1980's and 1990's concluded that there was a great deal of variability in the content and quality of information provided to candidates to prepare them for contemporary classrooms [4]. These studies also showed that newly prepared teachers who graduated from formal teacher preparation programs often did not feel adequately prepared to teach certain populations of students or to take on core teaching responsibilities.

A national movement in the 1990's resulted in the use of standards to prepare pre-service and practicing teachers to address these inconsistencies among teacher preparation pathways [5]. A large body of research supports the development of common frameworks and standards to improve the qual- 
ity of teacher preparation, with the ultimate goal of improving student outcomes [4]. This standards movement has coincided with "highly qualified teacher" and "evidence-based practices" requirements within the No Child Left Behind Act (P.L. 107-110).

Similar inconsistencies in the content and quality of instruction confront special education teacher preparation programs [6]. This discipline is further disadvantaged by the unique challenges facing the field of special education, including chronic and acute shortages of special education teachers [7]. These ongoing shortages have forced districts to hire teachers who lack appropriate certification and preparation [2].

Severe special education teacher shortages have also led to state polices which do not prepare special education teachers to teach specific disability categories, but instead require preparation and licensure of special educators to teach in non-categorical or multi-categorical disability categories [8]. These "catch-all" special education licensure categories force teacher preparation programs to sacrifice depth for breadth in their attempts to prepare teachers who can teach students with a wide variety of disability categories [9].

With such a sharp rise in the incidence of children with autism spectrum disorders (ASD), there is increased concern about the adequate preparation of special education teachers who can meet the unique needs of students with ASD and their families. A study by the Institute of Educational Sciences found that 46 percent of districts could not find qualified teachers to work with students with ASD [10]. Scheuermann et al. found that, besides chronic special educator shortages, the following obstacles hindered the preparation of effective teachers of students with ASD: a) lack of specific, in-depth knowledge provided to pre-service teachers regarding interventions and behavior management strategies for students with autism, and b) absence of accepted professional standards in autism [2].

To fill this void, the National Standard's Project was designed to address the need for evidencebased practices and guidelines for students with ASD [3]. The National Standards Project reviewed and analyzed the current research to identify effective evidence-based practices for ASD. The project identified eleven established treatments, i.e., those that are supported by well-controlled studies, which provide benefits to individuals with ASD as well as twenty-one emerging treatments that showed promising results in the research. Additionally, California is one of only two states that have adopted standards and requirements specific to the teaching of students with ASD. Because these standards have only been implemented recently (the state requirement for all pre-service teachers to take courses in evidencedbased autism teaching strategies took full effect in September 2011), the impact of these policies has not been studied.

\subsection{Teacher Efficacy Frameworks}

Bandura defined self-efficacy as "beliefs in one's capabilities to organize and execute the courses of action required to produce given attainments", $[11$, p. 4]. Bandura attributed four sources or experiences that help to build self-efficacy: verbal persuasion, physiological arousal, vicarious experiences (modeling), and mastery experiences (performance accomplishments). Bandura's self-efficacy theory places greater emphasis upon these last two sources, positing that vicarious experiences/modeling and mastery learning have the most powerful effects upon the development of selfefficacy [11]. By observing competent mentors and then modeling what s/he has observed, the learner forms a concept for new behavior patterns that later serve as guides for action. After observation and modeling, the learner then engages in mastery experiences. In this phase, the learner's initial behavioral patterns are further refined as s/he receives corrective feedback and/or performs self-corrective adjustments based on performance outcomes.

Teacher efficacy, a construct based upon Bandura's theory of self-efficacy, is a teacher's belief and confidence that s/he can bring about certain outcomes in student learning. Teacher efficacy has positive and significant effects on student outcomes [12]. Efficacious teachers also tend to persist longer in working with a student who is struggling [13].

Much of the research on teacher efficacy has focused on pre-service teachers. Pre-service teachers are individuals who have completed university coursework in subject matter and pedagogical practices, but have not yet entered into their capstone experience of student teaching. The findings of these studies show that, among pre-service teachers, confidence and efficacy prior to student teaching experiences are shown to have lasting effects on teaching efficacy over time [14].

There is a paucity of research that has investigated teacher efficacy among special education teachers. The few studies found in the published literature showed results that are consistent with findings on teacher efficacy among general education teachers. For example, Allinder [15] found that resource teachers high in personal efficacy tended to exhibit greater organization, fairness, enthusiasm, and clarity in instruction. These educators were also more inclined to exhibit a "willingness to try a vari- 
ety of materials and approaches to teaching, desire to find better ways of teaching, and implementation of progressive and innovative techniques" (p. 89). Another study by Coladarci and Breton [16] examined the relation between teacher efficacy and the frequency and utility of peer supervision that special education teachers received. Coladarci and Breton found that peer supervision and feedback were positively and significantly correlated to higher teacher efficacy.

Few studies have focused upon the efficacy of pre-service special education teachers. These notable exceptions [17] reveal that pre-service special education teachers and special education teacher interns (teachers who are provisionally licensed to teach while they are enrolled in university- or district-sponsored teacher preparation programs) face challenges that significantly impact on their development of teacher efficacy.

\subsection{Teachers' perceived readiness and effica- cy to teach students with ASD}

To date, teacher efficacy for teaching students with ASD has not been well studied. This is not surprising due to the lack of ASD coursework in teacher preparation courses. Barnhill and colleagues [18] surveyed 87 teacher preparation programs at institutions of higher education in the US, they found that $41 \%$ of the institutions did not offer any ASD specific coursework. Interestingly, $77 \%$ of the remaining special education teacher programs reported that it has only been in the past one to seven years that specialized courses in ASD have been offered.

Among those studies that investigated teacher's perceived readiness and efficacy to teach autism, Ruble [19] found that teachers of students' with ASD require direct access to expertise and modeling of instructional strategies designed for children with ASD. In another study, Jennet, Harris, and Mesibov [20] concluded that teachers who had extensive hands-on trained in a specific intervention for students with ASD (either ABA or TEACCH) scored high on a teacher efficacy rating scale. These studies lend support to Bandura's idea that self-efficacy is nurtured through vicarious experiences (modeling) and mastery learning, or hands-on experiences.

\subsection{Current Study}

Due to gaps in the research on the quality and content of teacher preparation of teachers of students with ASD, this study involved the development of a survey instrument that incorporated the
National Standards Project's eleven recommended treatments and the California-adopted Education Specialist Teaching and Other Related Services Credential Program Standards (2008, 2010). The purpose of the instrument was to provide the field with an understanding of which evidence-based treatments and skills were being successfully taught to pre-service teachers and whether one teacher preparation pathway favored pre-service teachers' confidence for implementing specific treatments over another.

Additionally, the authors designed the survey questions to acknowledge the important role of sources of self-efficacy emphasized in Bandura's [11] model. These sources are precursors to teacher efficacy, as Tschannen-Moran and colleagues demonstrated in their instrument validation study [14]. By incorporating the two most noteworthy of Bandura's four sources as a model from which to assess and develop the construct of teacher efficacy among pre-service teachers-modeling/observation and mastery learning - the authors theorized that there would be significant differences in pre-service teachers' confidence in their perceived knowledge, based upon their degree of exposure to vicarious experiences and observations, in carrying out specific treatments designed for students with ASD.

\section{Research questions}

1. Is the California Preparedness to Teach Students with Autism (CAPTSA) a valid measure of pre-service special educators' and special education intern teachers' perceived preparedness to carry out evidence-based treatments as outlined in the National Autism Standards Project?

2. Is the CAPTSA a valid measure of teacher competencies as outlined in the Education Specialist Teaching and Other Related Services Credential Program Standards (2008, 2010)?

\section{Methodology}

The study included the administration of this piloted survey instrument, based upon the National Standards Project (NSP) developed by the National Autism Center and upon new standards adopted by the state of California for teachers of students with ASD. Participants for this study consisted of 84 pre-service education specialist candidates and interns enrolled in four Institutes of Higher Education 
(IHEs) that offer California-accredited special education (education specialist) teacher preparation programs.

During the final semester of their coursework, pre-service teachers at each participating institute were asked to complete a 70 item survey regarding a) degree of knowledge regarding interventions and treatments found by the NSP to be "established treatments" or "emerging treatments". The development of the survey instrument and subsequent data analysis were conducted in order to determine 1) pre-service teachers' and interns' perceived knowledge of autism spectrum disorder and interventions; 2) whether they had observed the application of these treatments in a school setting; and 2) their degree of confidence in carrying out these interventions.

The survey was administered in both paper-andpencil and on-line format. For the latter, the researchers used proprietary software designed for this purpose. The dual delivery options were designed to accommodate pre-service teachers and interns who were attending courses held on campus and in distance learning delivery modes.

Prior to data analysis, names and identifiers on all surveys were removed and replaced with codes. Factor analyses were then conducted in order to determine whether the instrument had sufficient construct validity and to reduce the number of variables that are represented in the survey instrument.

Descriptive statistics were determined on item responses for Domains B-E of the instrument.

\subsection{Development of the instrument}

The pre-service survey was developed and reviewed by a team of researchers and faculty members from three of the IHEs participating in the study. The majority of the survey items are based upon the National Autism Center's National Standards Project [3]. Additional survey items were developed from California-adopted standards for the Added Authorization in ASD to address teacher knowledge and skills required for teaching students with ASD, including a) characteristics of ASD; b) teaching, learning, and behavioral strategies for students with ASD, and c) collaborating with other service providers and families in providing services to students with ASD.

The survey instrument consists of 70 questions/statements regarding pre-service teachers' and interns' perceptions of their knowledge of evidencebased practices for teaching students with ASD, as well as their perceived levels of confidence with in carrying out established treatments for students with
ASD. The following domains make up this survey instrument:

Part A: Demographic Information of Respondents

Part B: Characteristics of Students with ASD (CA-adopted standards)

Part C: $\quad$ Established Treatments for Students with ASD (National Standards Project)

Part D: Teaching Students with ASD (CAadopted standards)

Part E: Collaborating with Families and Other Professionals (CTC-adopted standards)

A 5-point Likert type scale was used for each question or statement in the survey. A " 1 " on the Likert type scale indicates "No knowledge" and a "5" indicates "Very knowledgeable" on questions and statements in which participants rate their knowledge level of treatments and teaching skills. A " 1 " indicates "Little/no confidence" in carrying out this treatment or teaching skill" and a " 5 " indicates "Very confident" in carrying out this treatment or teaching skill for questions and statements in which participants rate their ability to carry out specific treatments and teaching practices deemed important for teaching students with ASD.

\section{Results}

\subsection{Construct Validation of the Survey In- strument Using Exploratory Factor Analysis}

Factor analysis is a statistical technique that can be used to identify subsets of variables that are correlated with each other and also relatively uncorrelated with variables in other subsets of data. It is commonly used to summarize the pattern of correlations among a set of variables [21].

One of the main purposes of factor analysis is in the development of surveys for measuring proposed constructs, such as the survey used in this study, which was designed to measure 1) pre-service teachers' and interns' perceived knowledge of ASD and interventions; 2) whether they had observed the application of these treatments in a school setting; and 3) their degree of confidence in carrying out these interventions. In this study, the sets of survey questions in Parts B (Characteristics of Students with ASD), C (Established Treatments for Students with ASD, D (Teaching Students with ASD), and E (Collaborating with Families and Other Professionals) that were chosen for use in this survey were 
analyzed with the use of factor analysis to determine whether each set of items in each part of the survey inter-correlated in the way they should have.

A second purpose for the use of factor analysis is in data reduction, or to condense a large number of variables, such as the nine items in Part B, Knowledge of Characteristics of Students with ASD, in the survey used for this study, into a fewer number of variables, in this case, two variables represented by two factor scores. Further details about the creation of factors and latent variables are described in the following sections.

\subsection{Results of Factor Analysis on Part B, Characteristics of Students with ASD}

The exploratory principal components analysis on the Part B, Perceived Knowledge of Characteristics of Students with ASD subscale items using varimax rotation method yielded two components. Table 1 shows descriptive statistics for the characteristics items that were analyzed using factor analysis. Descriptive statistics are based on completed surveys; therefore the number may differ from the number of participants.

Table 1. Descriptive Statistics for Part B, Characteristics $(\underline{\mathrm{N}=79})$

\begin{tabular}{lcr}
\hline Item & Mean & $\begin{array}{c}\text { Standard } \\
\text { Deviation }\end{array}$ \\
\cline { 1 - 2 } Cognitive Functioning (1) & 4.19 & .74 \\
Communication Skills (2) & 4.43 & .78 \\
Language Development (2) & 4.14 & .89 \\
Social Differences (2) & 4.28 & .82 \\
Behavioral Challenges (2) & 4.43 & .67 \\
Auditory Processing (1) & 3.84 & .94 \\
Visual Processing (1) & 3.90 & .96 \\
Sensory Processing (1) & 4.13 & .93 \\
Praxis (Motor) Difficulties (1) & 3.68 & 1.04
\end{tabular}

After examining the grouping of the nine characteristics items into the two factors, the following descriptions for each factor were constructed.

- $\quad$ Sensory Processing (Factor 1). The items in this factor described the participants' perceived knowledge of the degree to which sensory processing affects the ASD student's ability to respond to instruction. The specific items that loaded on this factor are noted with (1) in Table 1.

- Communication/Social Skills (Factor 2). The items in this factor described the participants' perceived knowledge of the degree to which communication and social skills affect the ASD student's ability to respond to instruction. The specific items that loaded on this factor are noted with (2) in Table 1.

Appendix A shows the results from the factor analysis that prompted the descriptions of each factor. Eigenvalues greater than 1 were used to determine the number of factors in the characteristics variable because they represent the percentage of variance accounted for in that variable by the factor being measured. The larger a factor's eigenvalue, the more variance that particular factor accounts for in the variable. In this case, $71.39 \%$ of the variance in the characteristics variable was accounted for by these two factors. It was noted that the first factor, sensory processing, represented $54.24 \%$ of the variance in the characteristics variable. Of additional interest was the substantial difference between the eigenvalue of the first factor (4.88) and the eigenvalue of the second factor, communication/social skills (1.54). This finding will be kept in mind when choosing factors for future multiple regressions on the variable of characteristics. The remaining variance in the subscale of characteristics was unidentifiable and yielded eigenvalues of less than 1 .

\subsection{Results of Factor Analysis on Part $C$, Evidence-Based Practices}

The exploratory principal components analysis on the Part C, Perceived Knowledge of EvidenceBased Practices subscale items using varimax rotation method yielded nine components. Table 2 shows descriptive statistics for the evidence-based practices items that were analyzed using factor analysis.

Table 2. Descriptive Statistics for Part C, Evidence-Based Practices Items $(N=68)$

\begin{tabular}{ccr} 
Item & \multicolumn{2}{c}{ Mean $\begin{array}{c}\text { Standard } \\
\text { Deviation }\end{array}$} \\
\cline { 1 - 2 } Antecedent & & .77 \\
Knowledge (2) & 4.18 & 1.05 \\
Observation (3) & 3.66 & .84 \\
Practice (2) & 3.94 & .80 \\
Behavioral Packages & & .17 \\
Knowledge (7) & 4.16 & .87 \\
Observation (7) & 3.78 & 1.05 \\
Practice (7) & 3.96 & 1.31 \\
Comprehensive Behavioral Treatments & \\
Knowledge (1) & 3.34 & .13 \\
Observation (1) & 2.96 & .90 \\
Practice (1) & 3.16 & \\
Joint Attention Intervention & & \\
Knowledge (1) & 3.38 &
\end{tabular}




\begin{tabular}{lrr} 
Observation (1) & 2.91 & 1.19 \\
Practice(1) & 3.15 & .98 \\
Modeling & & \\
Knowledge (2) & 4.21 & .84 \\
Observation (3) & 3.72 & 1.18 \\
Practice (9) & 3.93 & .98 \\
Naturalistic Teaching Strategies & & \\
Knowledge (8) & 3.85 & .97 \\
Observation (3) & 3.32 & 1.31 \\
Practice (8) & 3.54 & 1.07 \\
Self-Management Interventions & & \\
Knowledge (4) & 3.90 & .87 \\
Observation (4) & 3.44 & 1.10 \\
Practice (4) & 3.60 & .88 \\
Peer Training Packages & & \\
Knowledge (4) & 3.40 & 1.01 \\
Observation (9) & 2.84 & 1.18 \\
Practice (9) & 3.18 & 1.18 \\
Story-Based Intervention Packages & \\
Knowledge (6) & 3.66 & 1.19 \\
Observation (6) & 3.15 & 1.34 \\
Practice (6) & 3.40 & 1.24 \\
Pivotal Response Treatment (PRT) & \\
Knowledge (1) & 3.29 & 1.12 \\
Observation (1) & 2.78 & 1.13 \\
Practice (1) & 2.96 & 1.13 \\
Schedules-based Intervention & & \\
Knowledge (5) & 4.01 & .92 \\
Observation (5) & 3.69 & 1.20 \\
Practice (5) & 3.79 & 1.07 \\
\hline \\
\hline
\end{tabular}

After examining the grouping of the 33 evidencebased practices items into the nine factors, the following descriptions for each factor were constructed.

- Overall knowledge, observations, and ability to implement widespread interventions (Factor 1). The items in this factor described the participants' perceived knowledge, observations, and ability to implement pivotal response treatment (PRT) to increase widespread improvement in a wide range of areas, such as motivation to engage in social communication, self-initiation, self-management, and responsiveness to multiple cues. The items in this factor also described the participants' perceived knowledge, observations, and ability to implement joint attention interventions, which build on foundational skills that regulate interactions with others. Finally, the items in this factor described the participants' perceived knowledge, observations, and ability to implement early intensive behavioral in- terventions. Specific items that loaded on this factor are noted with (1) in Table 2.

- Knowledge and practice in antecedent interventions and knowledge in modeling (Factor 2). The items in this factor described the participants' perceived knowledge and practice of the degree to which they can help ASD students to modify situational events that precede the occurrence of a problem behavior. One item in this factor described the participants' perceived knowledge of modeling interventions. The specific items that loaded on this factor are noted with (2) in Table 2.

- Various observations of antecedent, modeling, and naturalistic teaching strategies (Factor 3). The items in this factor described the participants' perceived observations of antecedent interventions, modeling, and naturalistic teaching strategies. The specific items that loaded on this factor are noted with (3) in Table 2 .

- Knowledge, observations, and practices of self-management interventions (Factor 4). The items in this factor described the participants' perceived knowledge, observations and practices of self-management interventions as well as knowledge of peer training packages. The specific items that loaded on this factor are noted with (4) in Table 2.

- Knowledge, observations, and practices of schedules-based intervention (Factor 5). The items in this factor described the participants' perceived knowledge, observations, and practices of schedules-based intervention. The specific items that loaded on this factor are noted with (5) in Table 2.

- Knowledge, observations, and practices of story-based intervention (Factor 6). The items in this factor described the participants' perceived knowledge, observations, and practices of story-based intervention. The specific items that loaded on this factor are noted with (6) in Table 2.

- Knowledge, observations, and practices of behavioral packages (Factor 7). The items in this factor described the participants' perceived knowledge, observations, and practices of behavioral packages, which refer to interventions that are designed to teach functional alternative behaviors or skills to replace problem behaviors. The specific items that loaded on this factor are noted with (7) in Table 2.

- Knowledge and practices of naturalistic teaching strategies (Factor 8). The items in this factor described the participants' per- 
ceived knowledge and practices of naturalistic teaching strategies. The specific items that loaded on this factor are noted with $(8)$ in Table 2 .

- Practice of modeling and peer-training packages, and observations of peer-training packages (Factor 9). The items in this factor described the participants' perceived practice of modeling and peer-training packages, and observations of peer-training packages. The specific items that loaded on this factor are noted with (9) in Table 2.

Appendix B shows the results from the factor analysis that prompted the descriptions of each factor. Once again, eigenvalues greater than 1 were used to determine the number of factors in the evidence-based practices variable because they represent the percentage of variance accounted for in that variable by the factor being measured. In this case, $85.43 \%$ of the variance in the evidence-based practices variable was accounted for by these nine factors. It was noted that the first factor, overall knowledge, observations, and ability to implement widespread interventions, represented $40.00 \%$ of the variance in the evidence-based practices variable. Of additional interest was the substantial difference between the eigenvalue of the first factor (14.40) and the eigenvalues of the second factor, (3.87), the third factor, (3.19), and the fourth factor (2.20). This finding will be kept in mind when choosing factors for future multiple regressions on the variable of characteristics. The last five factors yielded eigenvalues ranging from 1.87 to 1.09 . Finally, the remaining variance in the subscale of characteristics was unidentifiable and yielded eigenvalues of less than 1 .

\subsection{Results of Factor Analysis on Part D, Teaching Students with ASD}

The exploratory principal components analysis on the Part D, Teaching Students with ASD subscale items using varimax rotation method yielded only one component. The solution therefore could not be rotated. The nine items in the teaching subscale seemed to be conceptually similar in that they all described the perceptions of participants' ability to assess, analyze data, collaborate with professionals and families, and individualize instruction to meet the needs of various students with ASD in the nine areas they were queried about. The nine items were therefore merged into the variable we called teaching. Table 3 shows descriptive statistics for the nine teaching items.
Table 3. Descriptive Statistics for Teaching Items $(\mathrm{N}=80)$

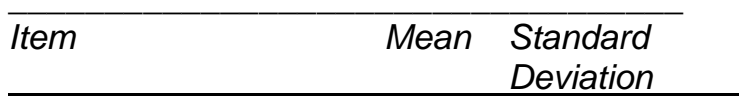

Teaching Students with ASD:

$\begin{array}{lll}\text { Unique Need } & 4.20 & .72 \\ \text { Communication Needs } & 4.16 & .68 \\ \text { Language Needs } & 4.04 & .80 \\ \text { Social Interactions } & 4.33 & .71 \\ \text { Behavior Challenges } & 4.21 & .82 \\ \text { Structured Learning } & 4.18 & .85 \\ \text { Schedules/Routines } & 4.45 & .61 \\ \text { Visual Strategies } & 4.33 & .73 \\ \text { Positive Learning Env. } & 4.40 & .69\end{array}$

Once again, eigenvalues greater than 1 were used to determine the number of factors in the teaching variable. In this case, $66.67 \%$ of the variance in the teaching variable was accounted for by all nine items in the teaching subscale. The eigenvalue was 7.33, which is a substantial eigenvalue. This larger eigenvalue will be kept in mind when computing multiple regressions with the teaching variable. The rest of the variance in the subscale of teaching was unidentifiable and yielded eigenvalues of less than 1 (See Appendix C).

\subsection{Results of Factor Analysis on Part E, Collaborating with Other Professionals}

The exploratory principal components analysis on the Part E, Collaborating with Other Professionals subscale items using varimax rotation method yielded two components. Table 4 shows descriptive statistics for the characteristics items that were analyzed using factor analysis.

Table 4. Descriptive Statistics for Part E, Collaboration Items $(\mathrm{N}=78)$

\begin{tabular}{rr}
\hline Item Mean $\begin{array}{c}\text { Standard } \\
\text { Deviation }\end{array}$ \\
\hline
\end{tabular}

Understanding of Roles/Responsibilities of:

$\begin{array}{lcc}\text { Psychologist (1) } & 4.29 & .97 \\ \text { Pathologist (1) } & 4.46 & .78 \\ \text { Occupational Therapist (1) } & 4.23 & .98 \\ \text { Physical Educator (1) } & 4.32 & .89 \\ \text { Paraprofessional (1) } & 4.63 & .65 \\ \text { Outside Agencies (1) } & 3.82 & 1.02\end{array}$


Skills/Strategies for Collaboration with:

$\begin{array}{lll}\text { Service Providers (2) } & 4.37 & .76 \\ \text { Families (2) } & 4.42 & .66 \\ \text { Recommendations (2) } & 4.31 & .78\end{array}$

After examining the grouping of the nine characteristics items into the two factors, the following descriptions for each factor were constructed.

- Roles of Service Providers (Factor 1). The items in this factor described the participants' perceived understanding of the roles and responsibilities of various service providers, such as psychologists, speech-language pathologists, and adapted physical educators. The specific items that loaded on this factor are noted with (1) in Table 4.

- Collaboration Skills and Strategies (Factor 2). The items in this factor described the participants' perceived confidence in their skills and knowledge of strategies to collaborate with service providers and families, including those from diverse backgrounds. One item in this factor also described the participants' confidence in their abilities to integrate the recommendations from multidisciplinary teams to build effective programs for ASD students. The specific items that loaded on this factor are noted with (2) in Table 4.

Appendix D shows the results from the factor analysis that prompted the descriptions of each factor. Once again, eigenvalues greater than 1 were used to determine the number of factors in the collaboration variable. In this final case, $74.46 \%$ of the variance in the collaboration variable was accounted for by these two factors. It was noted that the both of the factors, were closer in their representation of the total amount of variance in the collaboration variable, with roles of service providers providing an eigenvalue of 3.98 and collaboration skills and strategies providing an eigenvalue of 2.72. This finding will be kept in mind when choosing factors for future multiple regressions on the variable of collaboration. The remaining variance in the subscale of characteristics was unidentifiable and yielded eigenvalues of less than 1 .

In summary, the factor analysis on Part B, Perceived Knowledge of Characteristics of ASD Students, yielded two factors, with the first factor, sensory processing, accounting for most of the variance when compared to the other factor, communication/social skills (see Table 1 and Appendix A). The factor analysis on Part C, Perceived Knowledge of
Evidence-Based Practices, yielded nine factors with the first factor, overall knowledge, accounting for most of the variance when compared to the other eight factors (see Table 2 and Appendix B). The factor analysis on Part D, Perceived Knowledge of Teaching Students with ASD produced only one factor, teaching, which accounted for most of the variance in that variable (see Table 3 and Appendix C). Finally, the factor analysis on Part E, Perceived Knowledge of Collaborating with Other Professionals produced two factors, with both factors, roles of service providers and collaboration skills and strategies producing comparable amounts of the variance in that factor (see Table 4 and Appendix D).

\section{Conclusion \& implications}

The factor analysis that was computed in this study did indeed determine the construct validity of the survey. In other words, it determined whether the survey used measured that which it was designed to measure: 1) pre-service teachers' and interns' perceived knowledge of ASD and interventions; 2) whether they had observed the application of these treatments in a school setting; and 3) their degree of confidence in carrying out these interventions. This was seen in the characteristics of the factors created from the items in the various subscales of the survey.

The factors produced by each factor analysis of the survey's subscales reflected the constructs that the subscales were created to measure. For example, in Part B, which was constructed to measure the perceived knowledge of characteristics of students with ASD, the constructs that emerged were the interns' perceived knowledge of the characteristics of sensory processing and communication/social skills of students with ASD.

Part E, produced a more complex and somewhat ambiguous set of factors, except for the first factor. The remaining factors were more numerous than in the other subscales. This was interpreted as meaning that fewer items in this particular subscale loaded on any one factor, except for the first factor, which measured the interns' perception of their overall knowledge, observations and ability to implement a wide variety of interventions. Although this factor produced a large eigenvalue (14.40) and accounted for $40.00 \%$ of the total variance in this variable, the other eight factors produced collectively accounted for $45.43 \%$ of the total variance in the evidence-based practices variable, yet were more difficult to characterize (see Table 2). This led us to believe that perhaps the items in this subscale of the survey need to be further refined in a future version of the survey to better reflect the interns' perception of their knowledge, prior observations of, and ability to im- 
plement, or put into practice, specific types of treatments or interventions they were queried about.

The results of this survey shed some interesting light on how pre-service teachers gain knowledge of the different treatments. Some strategies appear be easier to observe than others, or perhaps master teachers are more efficient at implementing certain treatments over others. This was observed in the results from this survey. Treatments with clearly defined observable steps (e.g. Modeling, Schedulebased and Self-Management interventions) received higher observation and practice scores than treatments that are embedded in instruction and perhaps difficult to readily observe (PRT, Joint attention). Comprehensive treatments that target preschoolers also score low on observation by the pre-service special education teachers.

Teaching students with ASD is a task of monumental proportions. The increase in the number of students with ASD, coupled with the complex needs of students with ASD and wide range of characteristics requiring an individualized approach for each student, is putting an enormous strain on the education system. Preparing special education teachers to be effective interventionists in eleven treatments is an untenable and unrealistic goal, given the limitations of service hours and the expertise of university faculty and master teachers.

The preliminary results of this validation study suggest that, teacher preparation programs may be wise to identify treatments that are observable and implemented well by master teachers in their area and focus on these in their program while providing information about other available treatments. Prior research has demonstrated that pre-service teachers benefit from observing expert practitioners and hands on practice [19]; options that are only available if that treatment is being carried out in the classroom. In light of this, proficiency in a limited number of treatments may provide a sufficient base for special education teachers to build upon. This survey may be valuable in helping teacher preparation programs identify the treatments that are employed in local classrooms. Hands on assignments may be designed to provide an in-depth study of a particular treatment leading to a pre-service teacher who has the knowledge and confidence to work with students with ASD.

\subsection{Future research}

The results of the exploratory factor analyses will be used in a future study to help determine latent variables for demographics and perceived levels of confidence in carrying out established treat- ments for students with ASD. The exploratory factor analyses will be used in the process of conceptual modeling to design a model for regression analysis. A set of predictor variables will be selected using the latent variables with factor scores as dependent variables rather than raw scores from individual survey items. This further analysis will help to answer the questions of 1) pre-service teachers' and interns' perceived knowledge of ASD and interventions; 2) whether they had observed the application of these treatments in a school setting; and 3) their degree of confidence in carrying out these interventions.

\section{References}

[1] Center for Disease Control and Prevention. Prevalence of autism spectrum disorders-Autism and Developmental Disabilities Monitoring Network, fourteen sites, United States, 2008. MMWR Surveillance Summary 2012, 61(SS03), Center for Disease Control and Prevention, Atlanta, Georgia, USA, 2012, 1-19.

[2] Scheuermann, B., Webber, J., Goodwin, M., \& Boutot, A. Issues in teacher education in autism. Focus on Autism and Developmental Disabilities, Sage Publications, California, USA, 2003, 197-206.

[3] National Autism Center. National standards project: Addressing the need for evidence-based guidelines for autism spectrum disorders. National Autism Center, Randolph, MA, USA, 2009.

[4] Darling-Hammond, L. Chung, R., \& Frelow, F. Variation in teacher preparation: How well do different pathways prepare teachers to teach? Journal of Teacher Education, Sage Publications, California, USA, 2002, 286-302.

[5] Clune, W. H. Toward a Theory of Standards-based Reform: The Case of Nine NSF Statewide Systemic Initiatives. In S. H. Fuhrman (Ed.), From the Capitol to the Classroom: Standards-based Reform in the States. National Society for the Study of Education, Chicago, Ill., USA, 2001, pp. 286.

[6] National Comprehensive Center for Teacher Quality, N Navigating highly qualified teacher requirements for special education teachers: State challenges and responses. National Comprehensive Center for Teacher Quality, Washington, D. C., 2009.

[7] Carlson, E., Chen, L., Schroll, K., \& Klein, S. Study of personnel needs in special education [SPeNSE]. U.S. Department of Education, Office of Special Education and Rehabilitative Services, Washington, D. C., 2002.

[8] Mainzer, R. \& Horvath, M. Issues in preparing and licensing special educators. Professional Standards and Practice Committee, Council for Exceptional Children Monograph, Virginia, USA, 2001. 
[9] Ludlow, B. L., Conner, D., \& Schechter, J. Low incidence disabilities and personnel preparation tor rural areas: Current status and future trends. Rural Special Education Quarterly, American Council on Rural Special Education, West Virginia, USA, 2005, 15-24.

[10] Institute of Educational Sciences, I. National assessment of IDEA overview (NCEE 2011-4026). National Center for Educational Evaluation and Regional Assistance, Instituteof Educational Sciences, U.S. Department of Education, Alexandria, VA. USA, 2011.

[11] Bandura, A. Self-efficacy: The exercise of control. W.H. Freeman, New York, NY, USA, 1997.

[12] Burley, W. W., Hall, B. W., Villeme, M.G., \&

Brockmeier, L. L. A path analysis of the mediating role of efficacy in first-year teachers' experiences, reactions, and Efficacy and Teaching plans. Paper presented at the annual meeting of the American Educational Research Association, Chicago, Ill. USA, 1991.

[13] Gibson, S. \& Dembo, M. Teacher efficacy: A construct validation. Journal of Educational Psychology, American Psychological Association, Washington, D.C., 1984, 569-582.

[14] Tschannen-Moran, M. and Hoy, A. W. The differential antecedents of self-efficacy beliefs of novice and experienced teachers. Teaching \& Teacher Education. Elsevier B.V., The Netherlands, 2007, 944 - 956.

[15] Allinder, R. M. An examination of the relationship between teacher efficacy and curriculum-based measurement and student achievement, remedial and special education. Remedial \& Special Education, Sage Publications, USA, 1995, 247.

[16] Coldarci, T. and Breton, W. A. Teacher efficacy, supervision, and the special education resource-room teacher. The Journal of Educational Research, University of Illinois, Champaign, Il., USA, 1997, 230-239.

[17] Garberoglio, C. L., Gobble, M. E., \& Cawthorn, S. W. A national perspective on teachers' efficacy beliefs in deaf education. Journal of Deaf Studies and Deaf Education, Oxford University Press, Oxford, UK, 2012, 367-383.

[18] Barnhill, G., Polloway, E. \& Sumutka, B. A survey of personnel preparation practices in autism spectrum disorders. Focus on Autism and Other Developmental Disabilities, Sage Publications, USA, 2011, 75-86.

[19] Ruble, L. Randomized controlled study of COMPASS consultation for students with autism. Paper presented at the Kentucky Association of Psychology in the Schools. Lexington, KY, USA, 2011.

[20] Jennett, H.K., Harris, S.L., \& Mesibov, G.B. Commitment to philosophy, teacher efficacy, and burnout among teachers of children with autism. Journal of Autism and Developmental Disorders, Springer Publishing Company, New York, NY, USA, 2003, 583-593.
[21] Bordens, K. S. \& Abbott, B. B. Research design and methods: A process approach ( $3^{\text {rd }}$ ed.). Mayfield Publishing Company, Mountain View, CA, USA, 1996. 


\section{Appendix A}

Results of Factor Analysis on Part B, Characteristics Subscale

\begin{tabular}{lcr}
\hline Component & Eigenvalue* $^{*}$ & $\begin{array}{c}\text { Cumulative } \\
\text { Percentage } \\
\text { of Variance }\end{array}$ \\
\hline Sensory Processing & 4.88 & 54.24 \\
$\begin{array}{l}\text { Communication/ } \\
\text { Social Skills }\end{array}$ & 1.54 & 71.39 \\
\hline
\end{tabular}

*Eigenvalue greater than 1 was used as a criterion to determine the number of factors.

\section{Appendix B}

Results of Factor Analysis on Part C, EvidenceBased Practices Subscale

\begin{tabular}{cc}
\hline Component Eigenvalue* & $\begin{array}{c}\text { Cumulative } \\
\text { Percentage of } \\
\text { Variance_ }\end{array}$
\end{tabular}

Overall Intervention

Knowledge,

Observations,

and Practice

$14.40 \quad 40.00$

Knowledge and

Practice of

Antecedent

Interventions

$3.87 \quad 50.74$

Various

Observations

Self-Management

Interventions

Schedules-Based

Interventions

Story-Based

Interventions

Comprehensive

Behavioral

Treatments

79.32

Naturalistic

Teaching Strategies 1.11

Peer-Training Packages

And Modeling $\quad 1.09$ igenvalue greater than 1 was used as a criterion to determine the number of factors.

\section{Appendix C}

Results of Factor Analysis on Part D, Teaching. Students with ASD, Subscale

\begin{tabular}{lrc}
\hline Component & Eigenvalue* & $\begin{array}{c}\text { Cumulative } \\
\text { Percentage of } \\
\text { Variance }\end{array}$ \\
\hline Teaching & 7.33 & 66.67 \\
Unidentifiable & .94 & 75.22 \\
Unidentifiable & .74 & 81.99 \\
Unidentifiable & .43 & 85.88 \\
Unidentifiable & .35 & 89.07 \\
Unidentifiable & .30 & 91.82 \\
Unidentifiable & .27 & 94.29 \\
Unidentifiable & .23 & 96.38 \\
Unidentifiable & .19 & 98.13 \\
Unidentifiable & .11 & 99.10 \\
Unidentifiable & .10 & 100.00 \\
& &
\end{tabular}

*Eigenvalue greater than 1 was used as a criterion to determine the number of factors.

\section{Appendix D}

Results of Factor Analysis on Part E, Collaborating with Other Professionals, Subscale

Component $\quad$ Eigenvalue* $^{\text {Cumulative }}$
Percentage of
Variance

Roles of Service

$\begin{array}{lll}\text { Providers } & 3.98 & 44.27\end{array}$

Collaboration

Skills/Strategies $\quad 2.72 \quad 74.46$

*Eigenvalue greater than 1 was used as a criterion to determine the number of factors. 